\title{
Lysophosphatidic Acid Upregulates Laminin-332 Expression during A431 Cell Colony Dispersal
}

\author{
Hironobu Yamashita, ${ }^{1}$ Manisha Tripathi, ${ }^{1}$ Jerome Jourquin, ${ }^{1}$ Yoonseok Kam, ${ }^{2}$ \\ Shanshan Liu, ${ }^{1}$ Brandy Weidow, ${ }^{1}$ and Vito Quaranta ${ }^{1}$ \\ ${ }^{1}$ Department of Cancer Biology, Vanderbilt University Medical Center, Nashville, TN 37232, USA \\ ${ }^{2}$ Integrated Mathematical Oncology Department, H. Lee Moffitt Cancer Center, Tampa, FL 33612, USA \\ Correspondence should be addressed to Vito Quaranta, vito.quaranta@vanderbilt.edu
}

Received 16 March 2010; Revised 11 June 2010; Accepted 2 July 2010

Academic Editor: Therese Deramaudt

Copyright (C) 2010 Hironobu Yamashita et al. This is an open access article distributed under the Creative Commons Attribution License, which permits unrestricted use, distribution, and reproduction in any medium, provided the original work is properly cited.

\begin{abstract}
Lysophosphatidic acid (LPA) is a bioactive phospholipid that affects various biological functions, such as cell proliferation, migration, survival, wound healing, and tumor invasion through LPA receptors. Previously, we reported that LPA induces A431 colony dispersal, accompanied by disruption of cell-cell contacts and cell migration. However, it remains unclear how LPA affects cell migration and gene expression during A431 colony dispersal. In this paper, we performed cDNA microarray analysis to investigate this question by comparing gene expression between untreated and LPA-treated A431 cells. Interestingly, these results revealed that LPA treatment upregulates several TGF- $\beta 1$ target genes, including laminin-332 (Ln-332) components $(\alpha 3$, $\beta 3$, and $\gamma 2$ chains). Western blot analysis also showed that LPA increased phosphorylation of Smad2, an event that is carried out by TGF$\beta 1$ interactions. Among the genes upregulated, we further addressed the role of Ln-332. Real-time PCR analysis confirmed the transcriptional upregulation of all $\alpha 3, \beta 3$, and $\gamma 2$ chains of Ln-332 by LPA, corresponding to the protein level increases revealed by western blot. Further, the addition of anti-Ln-332 antibody prevented LPA-treated A431 colonies from dispersing. Taken together, our results suggest that LPA-induced Ln-332 plays a significant role in migration of individual cells from A431 colonies.
\end{abstract}

\section{Introduction}

Lysophosphatidic acid (LPA) is a phospholipid growth factor involved in a variety of physiological functions such as cellular proliferation, differentiation, migration, and survival $[1,2]$. In addition, it has also been shown to have a role in pathological conditions like wound healing and tumorigenesis [3]. LPA is naturally produced by many cells, including platelets, fibroblasts, and adipocytes; therefore, body fluids like serum, saliva, and other follicular fluids are a rich source of LPA [4-7]. It is well established that LPA signals various events through its $G$ protein-coupled receptors (GPCR), namely, LPA-1-4 [8].

During tumorigenesis, LPA is reportedly involved in both cell migration and invasion [9-12]. Many reports have shown that LPA plays an important role particularly in ovarian cancer, affecting various aspects of cancer development, including cellular proliferation, angiogenesis, migration, and survival $[13,14]$. It has also been shown that increased levels of LPA are found in the plasma of ovarian cancer patients, compared to disease-free subjects [15]. Normal ovarian epithelial cells produce trace amounts of LPA, whereas ovarian cancer cells produce LPA in large amounts [16]. Similarly, in prostate cancer, LPA is reported to induce proliferation and survival of androgen-independent prostate cancer cells $[17,18]$. In lung cancer, LPA has been shown to induce cellular migration [19]. LPA levels are also significantly increased in patients with myeloma, endometrial cancer, and cervical cancer [20,21]. Autotaxin, a soluble exoenzyme upregulated in cancer cells that increases cell invasion, has been found to stimulate proliferation and motility of cancer cells through LPA production [22], whereas autotaxin-dependent motility is blocked in LPA-1 deficient fibroblasts [23].

Previously, we have shown that LPA causes dispersal of epithelial cell colonies [24]. Our report demonstrated 
stepwise upregulation of cell motility features after treatment of A431 cells with LPA. Specifically, we noted the following changes: stimulation of lamellipodia formation, downregulation of cell-cell adhesion, and enhanced migration of the cells. In continuing this line of research, we have thus hypothesized that LPA changes cell motility by somehow affecting the cell microenvironment. To begin to test this hypothesis, in this study we performed microarray analysis of A431 cancer cells treated with LPA or PBS (for control) to examine the changes in microenvironment-related genes. Interestingly, microarray results revealed that LPA upregulates several TGF- $\beta 1$ target genes along with Ln-322, a major component of basement membrane. Several independent approaches also supported this finding.

\section{Materials and Methods}

2.1. Reagents. L- $\alpha$-lysophosphatidic acid (oleoyl, LPA $18: 1$ ) was purchased from Avanti Polar Lipids (Alabaster, AL) and stored at $-80^{\circ} \mathrm{C}$. Polyclonal antibody (pAb) against phosphorylated Smad2 (Ser465/467), GAPDH, and monoclonal antibody $(\mathrm{mAb})$ against $\mathrm{Smad} 2 / 3$ were purchased from Cell Signaling Technology (Danvers, MA), BD Biosciences (San Jose, CA), and Invitrogen (Carlsbad, CA), respectively. BM165 (mAb against human laminin $\alpha 3$ chain) was purchased from Life Technology Invitrogen (Carlsbad, CA). H-300 (pAb against human laminin $\beta 3$ chain) was purchased from Santa Cruz Biotechnology (Santa Cruz, CA). 2778, pAb against laminin $\gamma 2$ chain was prepared in-house, as previously described in $[25,26]$. MAb against $\beta$-actin was purchased from Sigma (St. Louis, MO). Anti-rabbit IgG or mouse IgG HRP-conjugated antibody was purchased from GE health care (Pittsburgh, PA).

2.2. Cell Culture. A431, a human epidermal squamous carcinoma cell line, was obtained from American Type Culture Collection (Manassas, VA), maintained in DMEM (Invitrogen), supplemented with 10\% fetal bovine serum (FBS; Invitrogen) and $2 \mathrm{mM}$ L-glutamine, and kept in constant culture in a humidified incubator with $5 \% \mathrm{CO}_{2}$ at $37^{\circ} \mathrm{C}$.

2.3. Immunoblot Analysis. To examine phosphorylation of Smad 2 and expression of Ln-332 chains by LPA, A431 cells were serum starved for $24 \mathrm{~h}$ and incubated with PBS or LPA (1-4 $\mu \mathrm{M})$ for indicated periods of time. Cells were lysed and $100 \mu \mathrm{g}$ of proteins were separated on $4-12 \%$ NuPAGE (BisTris) gels under reducing conditions. 3T3NIH cell lysates were purchased from Cell Signaling and used as a positive control (for Smad2 phosphorylation). After separation, the same gel was transferred to a PVDF membrane and blocked with $5 \%$ skim milk in $1 \mathrm{X}$ TBS and $0.1 \%$ Tween 20 . After the blocking step, pAb against phosphorylated Smad2 (pSmad2; Ser465/467), GAPDH, or mAb against $S m a d 2 / 3$ was added at the diluted ratio of $1: 1000$ and incubated at $4^{\circ} \mathrm{C}$ overnight. To check the expression of laminin $\alpha 3, \beta 3$, and $\gamma 2$ chains, BM165 mAb, H-300 pAb, or 2778 pAb was added at the diluted ratio of $1: 1000,1: 200,1: 2000$, respectively. MAb against $\beta$-actin was used as an internal control at the diluted
TABLE 1: Primers used for quantitative RT-PCR. For RT-PCR, we analyzed samples on an MiQ machine using a FastStart SYBR Green Master Mix, with the following primer sets.

\begin{tabular}{lcc}
\hline Gene & Primer set & $\begin{array}{c}\text { Gene accession } \\
\text { number }\end{array}$ \\
\hline LAMA3 & $5^{\prime}$-GGCTCACTCTGTATTGTTGG & NM_000227 \\
& $5^{\prime}$-ACAGAGACTGCTTTGGTGTG & \\
LAMB3 & $5^{\prime}$-TGATGGACAGGATGAAAGAC & NM_000228 \\
& $5^{\prime}$-GGAAGCTGTAGCATCACTTG & \\
LAMC2 & $5^{\prime}$-GAAGCCCAGAAGGTTGATAC & NM_005562 \\
& $5^{\prime}$-GTGAGTGTTCTGGAGCAAAG & \\
GAPDH & $5^{\prime}$-ATGACATCAAGAAGGTGGTG & NM_002046 \\
& $5^{\prime}$-CTGTAGCCAAATTCGTTGTC & \\
PPIA & $5^{\prime}$-CAAATGCTGGACCCAACACA & NM_021130 \\
& 5'-TGCCATCCAACCACTCAGTC & \\
\hline
\end{tabular}

ratio of $1: 10000$. Anti-rabbit IgG or mouse IgG HRPconjugated antibody was used as a secondary antibody at the diluted ratio of $1: 1000$ for $1 \mathrm{hr}$ at room temperature. The bands in all blots were visualized and imaged with an ECL plus system (Perkin Elmer, Waltham, MA). Band densities were quantified using ImageJ. Differences were examined with Student's $t$-test statistics using SPSS, version 17 (Chicago, IL), with $P$ values less than .05 accepted as significant.

2.4. RNA Extraction and cDNA Synthesis. To detect the expression level of laminin $\alpha 3, \beta 3$, and $\gamma 2$ chains in A431 cells, total RNA was isolated from cells treated with PBS or $1-2 \mu \mathrm{M}(1 \mu \mathrm{M}$ for microarray analysis and $2 \mu \mathrm{M}$ for real-time PCR) LPA using an RNAeasy kit (Qiagen, Germantown, MD). Total RNA digested with RQ RNasefree DNase I (Promega, Madison, WI) and OligoT primer (Roche, Madison, WI) was incubated for $10 \mathrm{~min}$ at $70^{\circ} \mathrm{C}$, chilled on ice, and added to a $20 \mathrm{ml}$ aliquot of a reaction mixture containing $4 \mu \mathrm{l}$ of Transcriptor RT reaction buffer (Roche), $1 \mu \mathrm{l}$ of $10 \mathrm{mM}$ mixture of four dNTPs, and $1 \mu \mathrm{l}$ of RNasin (Promega). In addition, $0.5 \mu \mathrm{l}$ of Transcriptor Reverse Transcriptase (Roche, Madison, WI) was added and incubation continued for $1 \mathrm{~h}$ at $55^{\circ} \mathrm{C}$. To stop the reaction, the reaction mixture was heated for $5 \mathrm{~min}$ at $85^{\circ} \mathrm{C}$ and then chilled on ice. To remove RNA contamination in the reaction mixture, RNase $\mathrm{H}$ (Promega) was added and incubated for $30 \mathrm{~min}$ at $37^{\circ} \mathrm{C}$. RNA integrity was determined by electrophoresis on a $1 \%$ agarose gel followed by visualization of intact $18 \mathrm{~S}$ and $28 \mathrm{~S}$ ribosomal RNA bands. RNA purity was measured using the $A_{260} / A_{280}$ ratio. To ensure that the optical density at $A_{260}$ was in the linear range, various concentrations of RNA were plotted against absorbance.

2.5. cDNA Microarray Analysis. Microarray experiments were performed by the Vanderbilt University Medical Center Microarray Core using Affymetrix Human U133 plus 2.0 chips according to manufacturer's instructions. Data were normalized using the Microarray Suite 5.0 algorithm. Due to our interest in particular genes, only some probe sets were analyzed, as shown in Table 1. 
Comparisons were made between RNA extracted from PBS-treated A431 cells and LPA-treated A431 cells $(N=2$, in triplicate). Differences were examined with Student's $t$-test statistics using SPSS, version 17 (Chicago, IL), with $P$ values less than .05 accepted as significant.

2.6. Quantitative Real-Time PCR (RT-PCR). For RT-PCR, we analyzed samples on a MiQ machine (Bio-Rad Laboratories, Hercules, CA) using a FastStart SYBR Green Master Mix (Roche, Madison, WI). The following primer sets were used, as shown in Table 1: LAMA3 (forward): $5^{\prime}$-GGCTCACTCTGTATTGTTGG, LAMA3 (reverse): 5'-ACAGAGACTGCTTTGGTGTG, LAMB3 (forward): 5' ${ }^{\prime}$-TGATGGACAGGATGAAAGAC, LAMB3 (reverse): 5'-GGAAGCTGTAGCATCACTTG, LAMC2 (forward): 5'-GAAGCCCAGAAGGTTGATAC, LAMC2 (reverse): 5'-GTGAGTGTTCTGGAGCAAAG, GAPDH (forward): 5' -ATGACATCAAGAAGGTGGTG, GAPDH (reverse): 5'-CTGTAGCCAAATTCGTTGTC. PPIA (forward): 5' -CAAATGCTGGACCCAACACA, PPIA (reverse): 5'-TGCCATCCAACCACTCAGTC. These primers were designed by open-source Primer3 software (http://primer3.sourceforge.net).

Comparisons were made between RNA extracted from PBS-treated A431 cells and LPA-treated A431 cells $(N=2$, in duplicate or triplicate). Differences were examined with Student's $t$-test statistics using SPSS, version 17 (Chicago, IL), with $P$ values less than .05 accepted as significant.

2.7. Cell Dispersal Assays. For dispersal assays, A431 cells were seeded at a density of $10^{4}$ cells $/ \mathrm{ml}$ in 6-well plates and allowed to grow for $24 \mathrm{~h}$. After formation of colonies, cells were cultured in serum-free DMEM for $24 \mathrm{~h}$ and then treated with PBS or LPA for $4 \mathrm{~h}$. Microscopy was conducted using a Zeiss Axiovert $200 \mathrm{M}$ microscope (Zeiss, Thornwood, $\mathrm{NY}$ ) equipped with a temperature- and $\mathrm{CO}_{2}$-controlled chamber ( 5 images per well, triplicate wells per treatment). Microscopy was under the control of OpenLab software (Improvision, Lexington, MA). To quantify cell behavior, we manually counted both the number of dispersed colonies and total colonies in each well of microplates. Differences were examined using two-way ANOVA with Bonferroni posttest using GraphPad Prism5 (La Jolla, CA), with values less than .05 accepted as significant. Data are presented as the mean \pm standard deviation ratio (percentage) of dispersed colonies to total number of colonies imaged.

\section{Results and Discussion}

We previously reported that LPA dramatically induces A431 squamous carcinoma cell colony dispersal, accompanied by disruption of cell-cell contacts and individual cell migration [24]. Herein, we analyzed gene expression of A431 cancer cells treated with LPA in order to better understand how LPA functions during cell colony dispersal. To this end, we first recapitulated experiments from our previous studies, whereas A431 cells were serum starved for $24 \mathrm{~h}$ and then treated with LPA $(1 \mu \mathrm{M})$ or PBS (for control) for $12 \mathrm{~h}$. After incubation, A431 cells were collected, and total RNA was

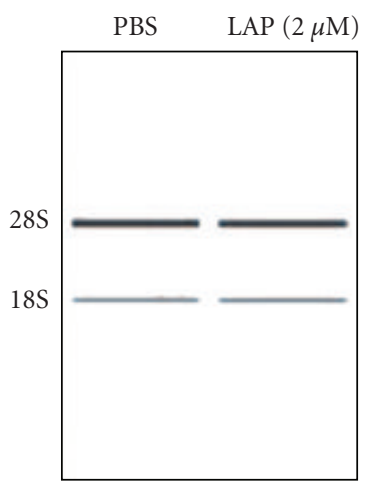

Figure 1: RNA preparation. A431 cells were incubated for $24 \mathrm{~h}$ in serum-deprived culture medium. LPA $(2 \mu \mathrm{M})$ or PBS (control) was added to medium and incubated for $12 \mathrm{~h}$ at $37^{\circ} \mathrm{C}$ in a humidified, $5 \% \mathrm{CO}_{2}, 95 \%$ air atmosphere. Total RNA was isolated from A431 cells treated with PBS or LPA $(2 \mu \mathrm{M})$ for 12 hrs, using a Qiagen RNeasy kit. The RNA integrity was measured by the RNA integrity number (RIN) software algorithm designed to classify the eukaryotic total RNA, based on numbering from 1 to 10 (1 indicates the most degraded RNA profile, and 10 indicates the most intact RNA). Electrophoresis of RNA in eukaryote total RNA Nano_DE114000902 resulted in an RNA integrity number (RIN) of 10.

extracted for cDNA microarray analysis. The RNA integrity was measured by the RNA integrity number (RIN) software algorithm designed to classify the eukaryotic total RNA, based on numbering from 1 to 10 ( 1 indicates the most degraded RNA profile, 10 indicates the most intact RNA). The RNA integrity number was checked by electrophoresis of RNA in Eukaryote Total RNA Nano_DE114000902. The RIN results of total RNA treated with PBS or LPA showed the number of 10, showing that both RNA samples are intact RNA (Figure 1 ).

Affymetrix cDNA microarray analysis was then performed to compare gene expression of A431cells treated with either LPA or PBS. Due to our interest in particular genes, only some probe sets were processed and analyzed for this study. Of note, laminin $\alpha 3$ (LAMA3), $\beta 3$ (LAMB3), and $\gamma 2$ chains (LAMC2), all components of the Ln-332 heterotrimer, were significantly upregulated in LPA-treated samples (Figure 2; $N=2$, in duplicate or triplicate; $P=.022$, .001 , and .019 , resp.). These results also revealed that several other genes involved in extracellular matrix were overexpressed in LPA-treated samples, including tenascin C, cysteine rich protein 61 , thrombospondin-1, and serine peptidase inhibitor or plasminogen activator inhibitor-1 (data not shown). Interestingly, all of these genes have been shown to be TGF- $\beta 1$ target genes [27-31].

The original observation on A431 colony dispersal has led us to further investigate cell phenotype epithelial-tomesenchymal transition (EMT), which is reportedly induced by TGF- $\beta 1$ in some cell systems and shows a disconnect between cells and dramatic changes in gene expression [32, 33]. TGF- $\beta 1$ is a protein that controls cell proliferation and growth in many cells, stimulates production of extracellular matrix proteins, and induces EMT, which is accompanied 


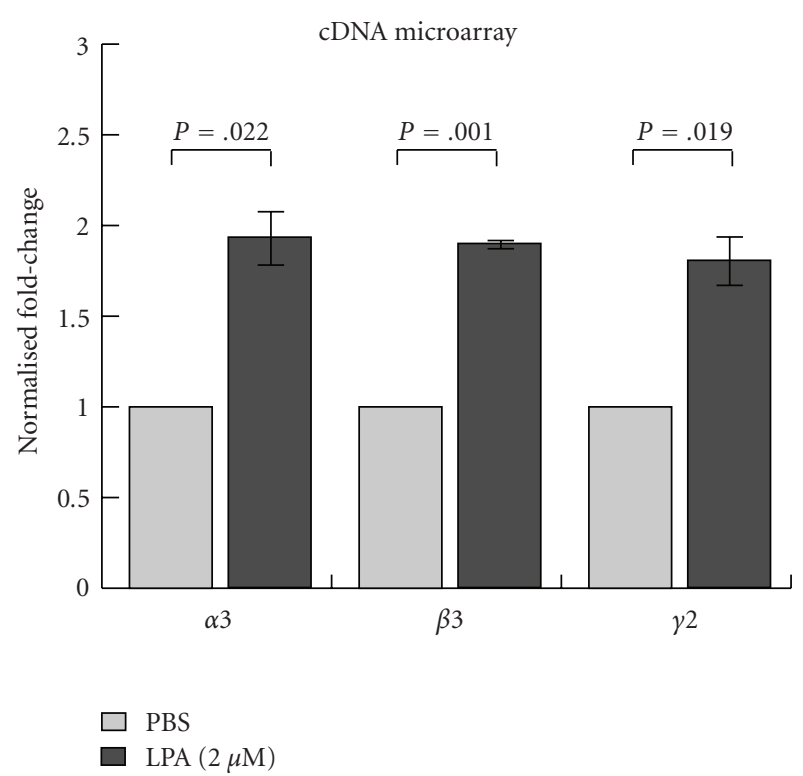

FIGURE 2: cDNA microarray analysis. Microarray analysis was performed on PBS and LPA-treated samples using Affymetrix Human U133 plus 2.0 chips according to manufacturer's instructions, and data were normalized using the Microarray Suite 5.0 algorithm. Among the upregulated genes induced by LPA, all three subchains of the intact Ln-332 molecule: $\alpha 3$ chain (LAMA3), laminin $\beta 3$ (LAMB3), and laminin $\gamma 2$ chain (LAMC2) were significantly increased.

by the decrease of cell-cell contacts and the increase of cell motility [24]. TGF- $\beta 1$ is known to bind and activate TGF- $\beta 1$ type I receptor (TGF $\beta$ R1), which phosphorylates receptorregulated Smad (R-Smad), Smad2, and Smad3 [34]. Phosphorylated Smad2/3 interacts with Smad4 to form complexes that translocate into cell nuclei, which leads to regulation of gene expression, either negatively or positively [34]. Recently, there were several reports suggesting the crosstalk between GPCR activated by LPA or sphingosine 1-phosphate and TGF $\beta$ signaling. For example, in keratinocytes, it has been reported that LPA induces TGF- $\beta 1$ signaling to mediate growth arrest and chemotaxis [35]. Therefore, we performed western blot analysis to determine whether LPA induces the phosphorylation of Smad2 in A431 cells, using an antiphospho-Smad2 antibody (3A). These results showed that, in contrast to the PBS control, LPA induced phosphorylation of Smad2 in A431 cells, although, of the concentrations we tested, only the highest dose, $4 \mu \mathrm{M}$, significantly enhanced phosphorylation (Figure 3(b)). Our results are in line with previous studies by Jeon et al. [36], which demonstrated that Smad2/3 is phosphorylated upon LPA stimulation and that it can be blocked using an LPA antagonist Ki16425. These findings suggest that LPA may also induce TGF- $\beta 1$ signaling in A431 cells.

Among the overexpressed genes induced by LPA, we further investigated the three subcomponents of the intact Ln-332 molecule: $\alpha 3$ chain, $\beta 3$, and $\gamma 2$ chains. Ln-332 is major basement membrane glycoprotein expressed mainly in epithelial cells that consists of these three chains in the form

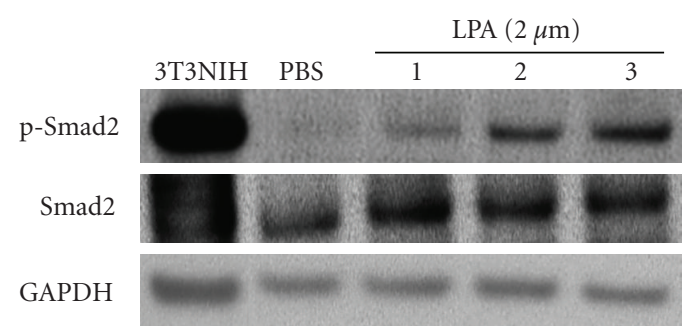

(a)

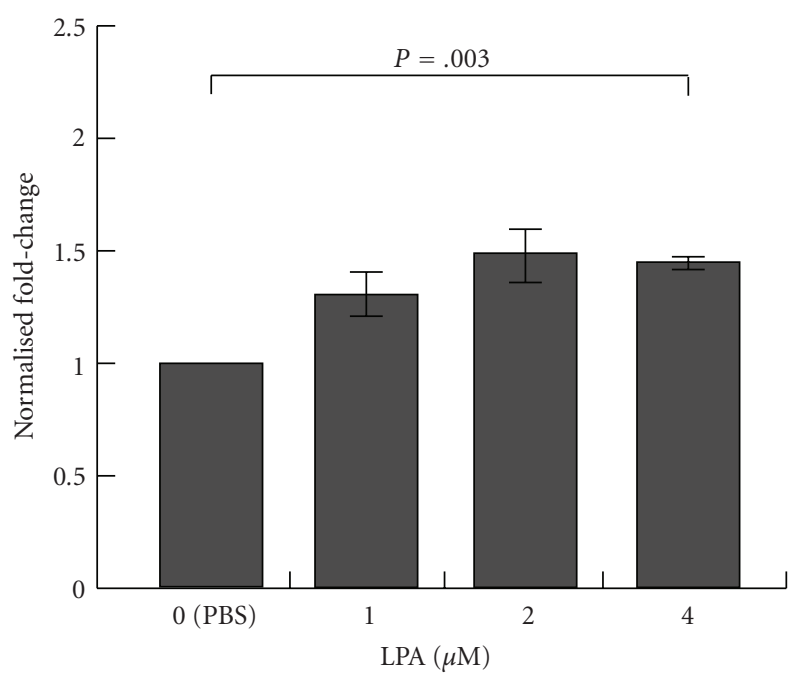

(b)

FIGURE 3: LPA induces phosphorylation of Smad-2 during A431 colony dispersal. A431 cells were serum starved for $24 \mathrm{~h}$ and incubated with PBS or LPA $(1,2$, or $4 \mu \mathrm{M})$ for $1 \mathrm{~h}$. (a, b) Cells were lysed and $100 \mu \mathrm{g}$ of total proteins were separated on $4-12 \%$ NuPAGE gels under reducing conditions. 3T3NIH cell lysate after TGF- $\beta 1$ treatment was used as a positive control for phosphorylation of Smad2. After separation, the same gel was transferred to a PVDF membrane and blocked with 5\% skim milk in $1 \mathrm{X}$ TBS and $0.1 \%$ Tween 20 . After blocking, a pAb against phosphorylated Smad2 (p-Smad2; Ser465/467), a mAb against Smad2/3, or GADPH was added at the diluted ratio of $1: 1000$ and incubated at $4^{\circ} \mathrm{C}$ overnight. Anti-rabbit IgG or mouse IgG HRPconjugated antibody was used as a secondary antibody at a diluted ratio of $1: 1000$. The bands were visualized with an ECL plus system. Protein expression levels were quantified from the western blots using ImageJ. Results showed that $4 \mu \mathrm{M}$ LPA treatment for $12 \mathrm{~h}$ significantly enhanced $\mathrm{pSmad} 2$ protein expression compared to $\mathrm{PBS}$ treatment $(N=3 ; P=.003)$.

of heterotrimer $\alpha 3 \beta 3 \gamma 2$ [36, 37]. Ln-332 plays a significant role in controlling cell behavior, such as cell adhesion, migration, and spreading via cell surface receptors, including integrin $\alpha 3 \beta 1$ and integrin $\alpha 6 \beta 4[37,38]$. We performed quantitative RT-PCR analysis using laminin primer sets shown in Table 1 to confirm the upregulation of the three laminin genes upon LPA treatment of A431 cells,. Realtime PCR analysis showed that LPA somewhat increased the expression of laminin $\alpha 3, \beta 3$, and $\gamma 2$ chains in A431 cells (by $\sim 2-2.5$-fold compared to PBS controls), although not significantly $(N=3 ; P=.11, .08$, and .13 , resp. $)$, 


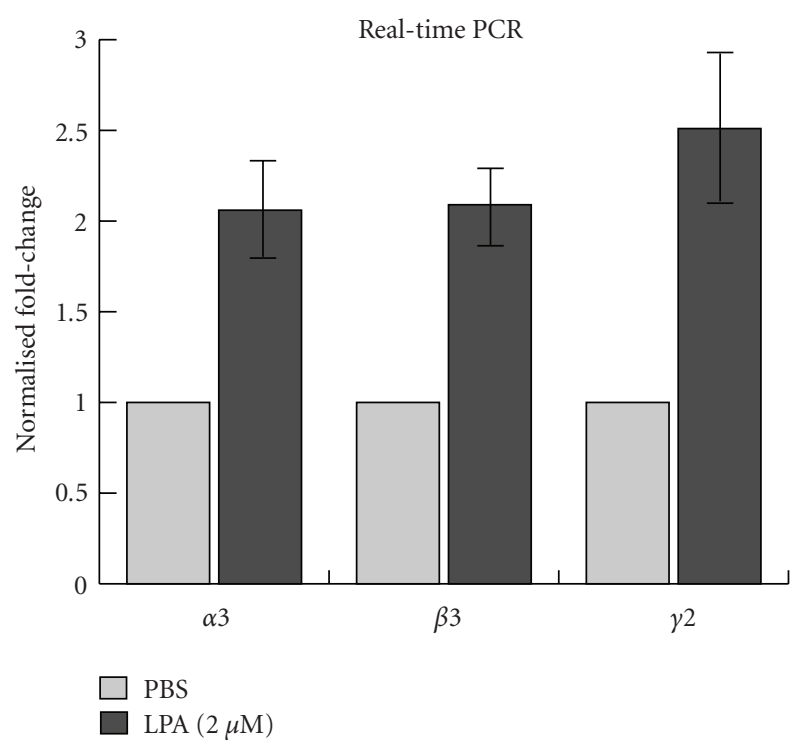

Figure 4: RT-PCR analysis of $m R N A$ expression of laminin $\alpha 3, \beta 3$, and $\gamma 2$ genes in LPA-treated A431 cells. To confirm the results of the previously performed microarrays, RT-PCR analysis was performed as described in Section 2. Briefly, A431 cells were treated with PBS or $2 \mu \mathrm{M}$ LPA for $12 \mathrm{~h}$, total RNA was extracted for each sample, and cDNA was synthesized using reverse transcriptase. Samples were analyzed on a MiQ machine using FastStart SYBR Green Master Mix. The primer sets used are shown in Table 1. Results showed that LPA treatment increased Ln-332 component, $\alpha 3, \beta 3$, and $\gamma 2$, expression (by $\sim 2-2.5$-fold), although results were not determined to be significantly different than PBS control treatments $(N=3$; $P=.11, .08$, and .13 , resp.).

suggesting that LPA may also induce laminin $\alpha 3, \beta 3$, and $\gamma 2$ gene expression at the mRNA level (Figure 4). However, additional studies are needed to confirm this finding.

Furthermore, western blot analysis using antibodies against individual laminin $\alpha 3, \beta 3$, and $\gamma 2$ chains also showed that protein expression increased after LPA treating of A431 cells. Ln-332 $\alpha 3$ and $\beta 3$ chains were significantly enhanced in LPA-treated cells, whereas $\gamma 2$ chain was only somewhat increased using this method (Figures 5(a) and 5(b)). Collectively, these results suggest that Ln-332 heterotrimer expression is also elevated after LPA treatment. Interestingly, various cytokines, growth factors, and LPA have previously been shown to promote the synthesis of Ln-332 in human keratinocytes [39]. Taken together, three independent approaches show that Ln-332 is enhanced at the cDNA, mRNA, and protein levels, respectively.

The binding and their role of Ln-332 and integrin receptors have been intensely studied in various physiological events [43]. Ln-332 can promote strong cell adhesion by interacting with $\alpha 6 \beta 4$ and intermediate filaments to form hemidesmosomes [37, 44-46] or can behave as a promigratory agent by binding to $\alpha 3 \beta 1[47,48]$. These functions are observed in normal skin and wound healing, respectively [37, 44, 45, 48]. Collectively, these findings lead us to believe that LPA-inducible Ln-332 promotes A431 cell colony dispersal, presumably by interaction with

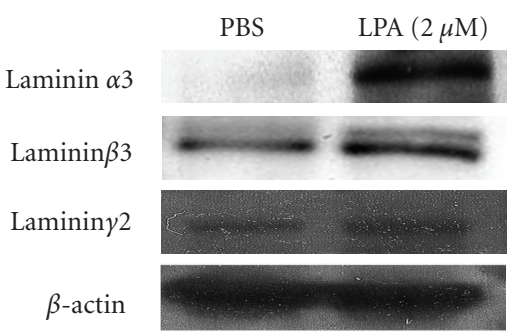

(a)

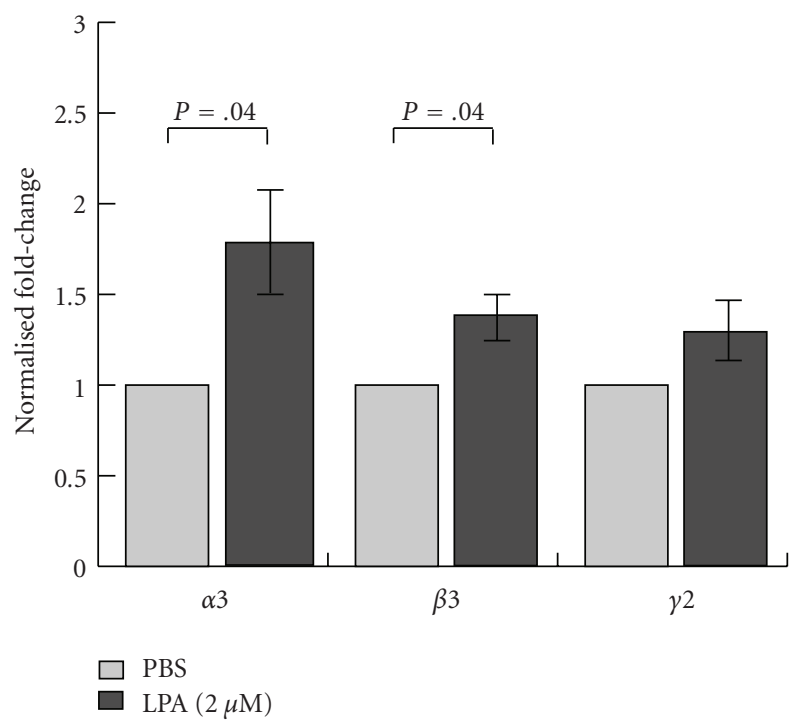

(b)

Figure 5: LPA enhances laminin-332 protein expression in A431 cells. To examine the expression level of Ln-332 chains in LPAtreated A431 cells, cells were serum starved for $24 \mathrm{~h}$ and incubated with PBS or $2 \mu \mathrm{M}$ LPA for $12 \mathrm{~h}$. (a, b) Cells were then lysed and $100 \mu \mathrm{g}$ of proteins were separated on an $8 \%$ gel under reducing conditions. After separation, the same gel was transferred to a PVDF membrane and blocked with 5\% skim milk in $1 \mathrm{X}$ TBS and $0.1 \%$ Tween 20. After blocking, BM165 (mAb against human laminin $\alpha 3$ chain) H-300 (pAb against human laminin $\beta 3$ chain), a pAb against rat laminin $\gamma 2$ chain, or a mAb against actin was added at the diluted ratios of $1: 1000,1: 200,1: 2000$, and $1: 10000$, respectively, and incubated at $4{ }^{\circ} \mathrm{C}$ overnight. Anti-rabbit IgG or mouse IgG HRP-conjugated antibody was used as a secondary antibody at the diluted ratio of $1: 1000$. The bands were visualized with an ECL plus system (Perkin Elmer, Waltham, MA). Protein expression levels were quantified using ImageJ. Results showed that LPA treatment consistently increased Ln-332 component expression. Both the Ln$332 \alpha 3$ and $\beta 3$ chains were determined to be significantly increased $(N=3, P=.004)$, whereas the $\gamma 2$ chain was only somewhat elevated compared to the PBS control treatment.

cell surface receptor integrins $\alpha 3 \beta 1$ or $\alpha 6 \beta 4$. While the experimentation necessary to unravel this hypothesis is still in early stages, we have obtained some data that supports this idea. Using cell colony dispersal assays similar to our previous studies [24], we have found that adding anti-Ln332 antibody to A431 cells almost completely blocked the dispersal of LPA-treated colonies (Figures 6(a) and 6(b)). These results strongly support a general role for Ln-332 in 


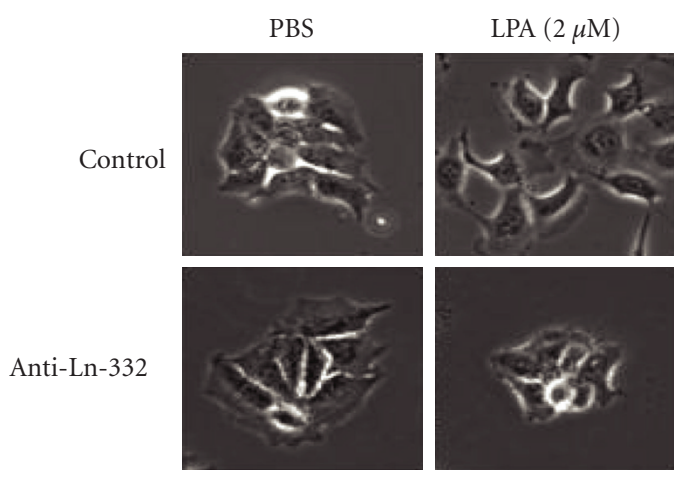

(a)

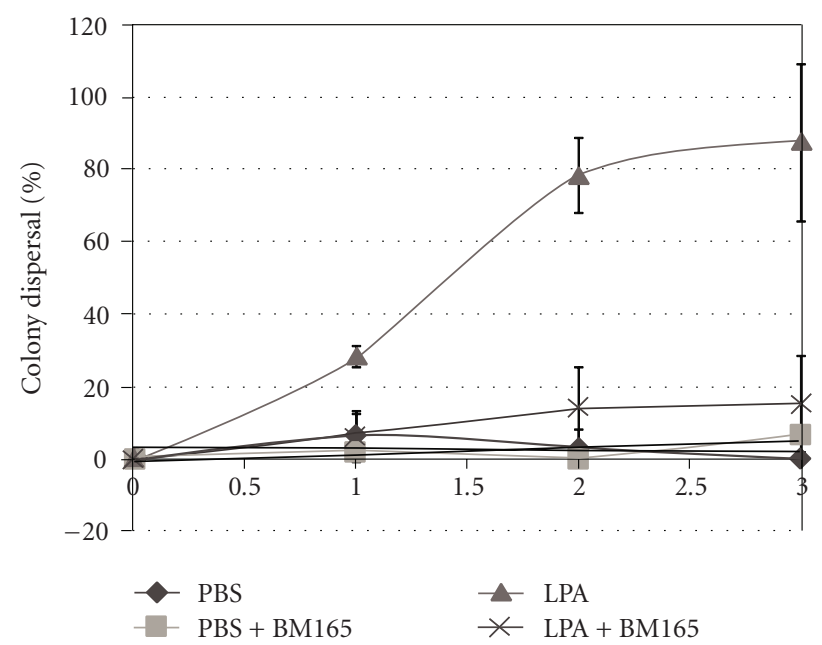

(b)

FIgURE 6: Anti-Ln-332 antibody prevents A431 colony from dispersing by LPA treatment. Cell colony dispersal assays were performed similarly to our previous studies (serum-starved A431 cells for $24 \mathrm{~h}$, treated with $2 \mu \mathrm{M} \mathrm{LPA}$ ), with the addition of an anti-Ln-332 antibody (BM165). (a, b) We found that anti-Ln-332 antibody significantly blocked dispersal of LPA-treated colonies, compared to those colonies treated with LPA alone $(N=3 ; P<.05)$. LPA-treated A431 colony dispersal percentages in the absence (LPA) or presence of BM165 antibody (LPA + antiLn-332) are indicated as light-grey triangles or cross, respectively. These results strongly support a general role for Ln-332 in regulating the "LPA effect". ${ }^{*} P<.05$, Two-way ANOVA (Bonferroni post test).

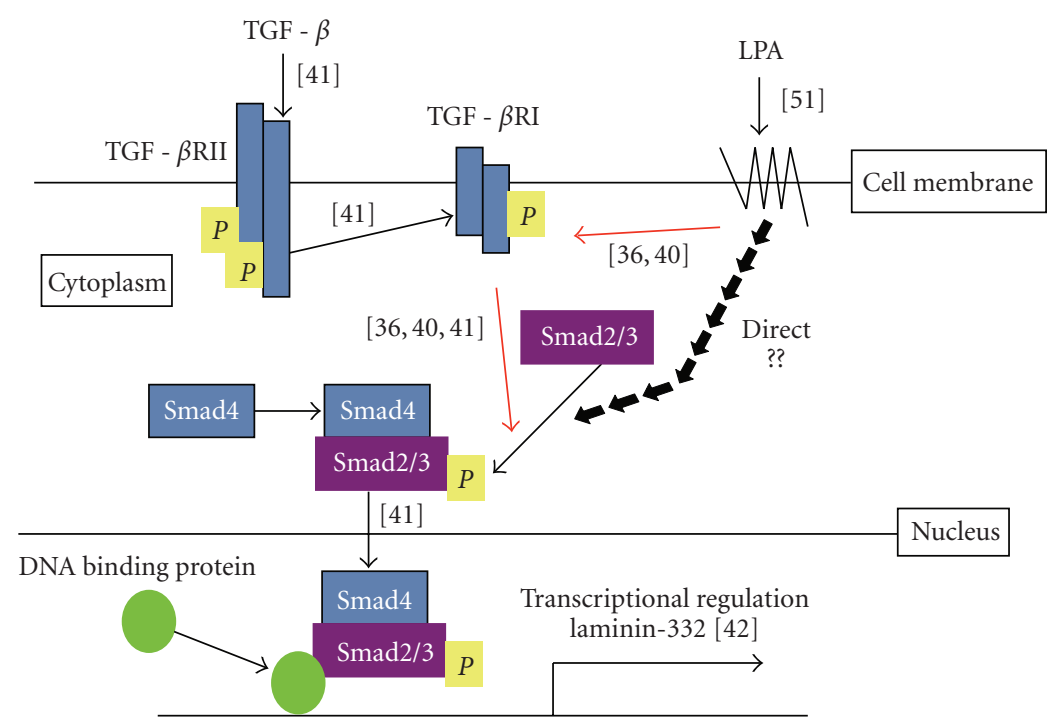

FIGURE 7: Hypothetical working model of LPA-induced A431 colony dispersal. We hypothesize that LPA induces Ln-332 expression via TGF- $\beta 1$ pathway. In our working model, LPA binds to LPA receptors on the A431 cell surface and transactivates TGF- $\beta 1$ type I receptor (TGF $\beta$ R1), which phosphorylates receptor-regulated Smad (R-Smad), Smad2, and Smad3. These results are supported by other previous findings [36, $40,41]$. Another potential pathway may lead to the direct induction of phosphorylation of Smad2/3.Phosphorylated Smad2/3 forms complex with Smad4 and translocates into the nucleus [41]. Smad4 functions as a positive transcriptional regulator of Ln-332 [42]. Finally, LPA enhances Ln-332 expression to promote A431 colony dispersal.

regulating the "LPA effect". In addition, preliminary studies have also shown that blocking antibodies against integrins $\alpha 3$ or $\beta 1$, but not $\alpha 6$, remarkably reduced LPA-treated A431 colony dispersal (data not shown). Our findings are in line with previous studies by Salo et al. [49], which showed that antibodies blocking Ln-332 inhibit cell adhesion and migration, subsequently leading to reduced tumor growth and invasion in vivo. However, we plan to tackle additional studies in the future to further investigate the specific role of LPA in these data. Of note, Giannelli et al. previously demonstrated that Ln-332 and TGF- $\beta 1$ cooperatively induce EMT in hepatocellular carcinoma [50].

In summary, we propose a working model of LPAinduced A431 colony dispersal (Figure 7). We hypothesize 
that LPA induces Ln-332 expression via the TGF- $\beta 1$ pathway. In our working model, LPA binds to LPA receptors on the A431 cell surface and transactivates TGF- $\beta 1$ type I receptor (TGF $\beta$ R1), which phosphorylates receptor-regulated Smad (R-Smad), Smad2, and Smad3 [36]. In addition, LPA potentially induces the direct phosphorylation of $S \operatorname{mad} 2 / 3$ via LPA receptors, or LPA-induced TGF- $\beta 1$ signals activate phosphorylation of $S \operatorname{mad} 2 / 3$.

Phosphorylated Smad2/3 forms complex with Smad4 and translocates into the nucleus. It has been reported that smad4 functions as a positive transcriptional regulator of Ln332 in colorectal cancer cell lines [42]. Through these potential pathways, LPA potentially enhances Ln-332 expression, leading to the promotion of A431 colony dispersal.

However, we recognize that our results could be the consequences of the activation of other pathways than TGF- $\beta$. In brief, we acknowledge that many previous studies have explored the downstream effectors of LPA, including RhoA, which is involved in contraction and cell rounding, Rac, which is involved in cell spreading and migration, Akt, which is involved in cell survival, and RAS, which is important in DNA synthesis and viability [51]. These multiple effects may explain why one compound, LPA, could have such a repertoire of cell responses.

\section{Conclusions}

Herein, we have reported that LPA induces TGF- $\beta 1$ target gene expression including Ln-332 during LPA-induced A431 colony dispersal, and we conclude that Ln-332 plays a significant role in promoting colony dispersal and single-cell migration, at least for the A431 cell line.

\section{Acknowledgments}

The authors acknowledge the following funding sources for support of this paper: National Institutes of Health Grant CA47858-17A2 awarded to VQ and VICTR voucher support VR303 awarded to HY.

\section{References}

[1] E. J. van Corven, A. Groenink, K. Jalink, T. Eichholtz, and W. H. Moolenaar, "Lysophosphatidate-induced cell proliferation: identification and dissection of signaling pathways mediated by G proteins," Cell, vol. 59, no. 1, pp. 45-54, 1989.

[2] W. H. Moolenaar, L. A. van Meeteren, and B. N. G. Giepmans, "The ins and outs of lysophosphatidic acid signaling," BioEssays, vol. 26, no. 8, pp. 870-881, 2004.

[3] S. Liu, M. Murph, N. Panupinthu, and G. B. Mills, "ATX-LPA receptor axis in inflammation and cancer," Cell Cycle, vol. 8, no. 22, pp. 3695-3701, 2009.

[4] G. Tigyi, D. L. Dyer, and R. Miledi, "Lysophosphatidic acid possesses dual action in cell proliferation," Proceedings of the National Academy of Sciences of the United States of America, vol. 91, no. 5, pp. 1908-1912, 1994.

[5] F. Gaits, O. Fourcade, F. Le Balle et al., "Lysophosphatidic acid as a phospholipid mediator: pathways of synthesis," FEBS Letters, vol. 410, no. 1, pp. 54-58, 1997.
[6] C. Pages, A. Girard, O. Jeanneton et al., "LPA as a paracrine mediator of adipocyte growth and function," Annals of the New York Academy of Sciences, vol. 905, pp. 159-164, 2000.

[7] T. Sano, D. Baker, T. Virag et al., "Multiple mechanisms linked to platelet activation result in lysophosphatidic acid and sphingosine 1-phosphate generation in blood," The Journal of Biological Chemistry, vol. 277, no. 24, pp. 21197-21206, 2002.

[8] N. Fukushima and J. Chun, "The LPA receptors," Prostaglandins and Other Lipid Mediators, vol. 64, no. 1-4, pp. 21-32, 2001.

[9] F. Imamura, T. Horai, M. Mukai, K. Shinkai, M. Sawada, and H. Akedo, "Induction of in vitro tumor cell invasion of cellular monolayers by lysophosphatidic acid or phospholipase D," Biochemical and Biophysical Research Communications, vol. 193, no. 2, pp. 497-503, 1993.

[10] D. A. Fishman, Y. Liu, S. M. Ellerbroek, and M. S. Stack, "Lysophosphatidic acid promotes matrix metalloproteinase (MMP) activation and MMP-dependent invasion in ovarian cancer cells," Cancer Research, vol. 61, no. 7, pp. 3194-3199, 2001.

[11] Y. Zheng, Y. Kong, and E. J. Goetzl, "Lysophosphatidic acid receptor-selective effects on Jurkat $\mathrm{T}$ cell migration through a matrigel model basement membrane," The Journal of Immunology, vol. 166, no. 4, pp. 2317-2322, 2001.

[12] A. Gschwind, S. Hart, O. M. Fischer, and A. Ullrich, "TACE cleavage of proamphiregulin regulates GPCR-induced proliferation and motility of cancer cells," The EMBO Journal, vol. 22, no. 10, pp. 2411-2421, 2003.

[13] G. B. Mills, A. Eder, X. Fang et al., "Critical role of lysophospholipids in the pathophysiology, diagnosis, and management of ovarian cancer," Cancer Treatment and Research, vol. 107, pp. 259-283, 2002.

[14] Y. Xu, Y. J. Xiao, K. Zhu et al., "Unfolding the pathophysiological role of bioactive lysophospholipids," Current Drug Targets. Immune, Endocrine \& Metabolic Disorders, vol. 3, no. 1, pp. 23-32, 2003.

[15] J. A. Roberts, "Searching for a biomarker for ovarian cancer," JAMA, vol. 280, no. 8, p. 739, 1998.

[16] X. Fang, D. Gaudette, T. Furui et al., "Lysophospholipid growth factors in the initiation, progression, metastases, and management of ovarian cancer," Annals of the New York Academy of Sciences, vol. 905, pp. 188-208, 2000.

[17] P. F. Kue, J. S. Taub, L. B. Harrington, R. D. Polakiewicz, A. Ullrich, and Y. Daaka, "Lysophosphatidic acid-regulated mitogenic ERK signaling in androgen-insensitive prostate cancer PC-3 cells," International Journal of Cancer, vol. 102, no. 6, pp. 572-579, 2002.

[18] Y. Daaka, "Mitogenic action of LPA in prostate," Biochimica et Biophysica Acta, vol. 1582, no. 1-3, pp. 265-269, 2002.

[19] T. Kusama, M. Mukai, M. Ayaki et al., "Inhiblition of lysophosphatidic acid-induced RhoA activation and tumor cell invasion by 3-hydroxy-3-methylglutaryl-coenzyme A reductase inhibitors," International Journal of Oncology, vol. 23, no. 4, pp. 1173-1178, 2003.

[20] T. Sasagawa, M. Okita, J. Murakami, T. Kato, and A. Watanabe, "Abnormal serum lysophospholipids in multiple myeloma patients," Lipids, vol. 34, no. 1, pp. 17-21, 1999.

[21] Y. Xu, Z. Shen, D. W. Wiper et al., "Lysophosphatidic acid as a potential biomarker for ovarian and other gynecologic cancers," JAMA, vol. 280, no. 8, pp. 719-723, 1998.

[22] E. J. Black, T. Clair, J. Delrow, P. Neiman, and D. A. F. Gillespie, "Microarray analysis identifies Autotaxin, a tumour cell motility and angiogenic factor with lysophospholipase D activity, as a specific target of cell transformation by v-Jun," Oncogene, vol. 23, no. 13, pp. 2357-2366, 2004. 
[23] K. Hama, J. Aoki, M. Fukaya et al., "Lysophosphatidic acid and autotaxin stimulate cell motility of neoplastic and nonneoplastic cells through LPA1," The Journal of Biological Chemistry, vol. 279, no. 17, pp. 17634-17639, 2004.

[24] J. Jourquin, N. Yang, Y. Kam, C. Guess, and V. Quaranta, "Dispersal of epithelial cancer cell colonies by lysophosphatidic acid (LPA)," Journal of Cellular Physiology, vol. 206, no. 2, pp. 337-346, 2006.

[25] S. Schenk, E. Hintermann, M. Bilban et al., "Binding to EGF receptor of a laminin-5 EGF-like fragment liberated during MMP-dependent mammary gland involution," Journal of Cell Biology, vol. 161, no. 1, pp. 197-209, 2003.

[26] N. Koshikawa, S. Schenk, G. Moeckel et al., "Proteolytic processing of laminin- 5 by MT1-MMP in tissues and its effects on epithelial cell morphology," The FASEB Journal, vol. 18, no. 2, pp. 364-366, 2004.

[27] M. Jinnin, H. Ihn, Y. Asano, K. Yamane, M. Trojanowska, and K. Tamaki, "Tenascin-C upregulation by transforming growth factor- $\beta$ in human dermal fibroblasts involves Smad3, Sp1, and Ets1," Oncogene, vol. 23, no. 9, pp. 1656-1667, 2004.

[28] C. P. Denton and D. J. Abraham, "Transforming growth factor- $\beta$ and connective tissue growth factor: key cytokines in scleroderma pathogenesis," Current Opinion in Rheumatology, vol. 13, no. 6, pp. 505-511, 2001.

[29] S. Dennler, S. Itoh, D. Vivien, P. T. Dijke, S. Huet, and J.-M. Gauthier, "Direct binding of Smad3 and Smad4 to critical TGF $\beta$-inducible elements in the promoter of human plasminogen activator inhibitor-type 1 gene," The EMBO Journal, vol. 17, no. 11, pp. 3091-3100, 1998.

[30] F. C. McGillicuddy, D. O’Toole, J. A. Hickey, W. M. Gallagher, K. A. Dawson, and A. K. Keenan, "TGF- $\beta 1$-induced thrombospondin-1 expression through the p38 MAPK pathway is abolished by fluvastatin in human coronary artery smooth muscle cells," Vascular Pharmacology, vol. 44, no. 6, pp. 469-475, 2006.

[31] M. M. Chen, A. Lam, J. A. Abraham, G. F. Schreiner, and A. H. Joly, "CTGF expression is induced by TGF- $\beta$ in cardiac fibroblasts and cardiac myocytes: a potential role in heart fibrosis," Journal of Molecular and Cellular Cardiology, vol. 32, no. 10, pp. 1805-1819, 2000.

[32] J. M. Lee, S. Dedhar, R. Kalluri, and E. W. Thompson, "The epithelial-mesenchymal transition: new insights in signaling, development, and disease," Journal of Cell Biology, vol. 172, no. 7, pp. 973-981, 2006.

[33] J. P. Thiery, H. Acloque, R. Y. J. Huang, and M. A. Nieto, "Epithelial-mesenchymal transitions in development and disease," Cell, vol. 139, no. 5, pp. 871-890, 2009.

[34] Y. Shi and J. Massague, "Mechanisms of TGF- $\beta$ signaling from cell membrane to the nucleus," Cell, vol. 113, no. 6, pp. 685700, 2003

[35] B. Sauer, R. Vogler, K. Zimmermann et al., "Lysophosphatidic acid interacts with transforming growth factor- $\beta$ signaling to mediate keratinocyte growth arrest and chemotaxis," Journal of Investigative Dermatology, vol. 123, no. 5, pp. 840-849, 2004.

[36] E. S. Jeon, H. J. Moon, M. J. Lee, et al., "Cancer-derived lysophosphatidic acid stimulates differentiation of human mesenchymal stem cells to myofibroblast-like cells," Stem Cells, vol. 26, no. 3, pp. 789-797, 2008.

[37] W. G. Carter, M. C. Ryan, and P. J. Gahr, "Epiligrin, a new cell adhesion ligand for integrin $\alpha 3 \beta 1$ in epithelial basement membranes," Cell, vol. 65, no. 4, pp. 599-610, 1991.

[38] C. M. Niessen, F. Hogervorst, L. H. Jaspars et al., "The $\alpha 6 \beta 4$ integrin is a receptor for both laminin and kalinin," Experimental Cell Research, vol. 211, no. 2, pp. 360-367, 1994.
[39] S. Amano, N. Akutsu, Y. Ogura, and T. Nishiyama, "Increase of laminin 5 synthesis in human keratinocytes by acute wound fluid, inflammatory cytokines and growth factors, and lysophospholipids," British Journal of Dermatology, vol. 151, no. 5, pp. 961-970, 2004.

[40] B. Sauer, R. Vogler, K. Zimmermann, et al., "Lysophosphatidic acid interacts with transforming growth factor- $\beta$ signaling to mediate keratinocyte growth arrest and chemotaxis," Journal of Investigative Dermatology, vol. 123, no. 5, pp. 840-849, 2004.

[41] J. Massagué, "TGF- $\beta$ signal transduction," Annual Review of Biochemistry, vol. 67, pp. 753-791, 1998.

[42] M. Zapatka, D. Zboralski, Y. Radacz et al., "Basement membrane component laminin-5 is a target of the tumor suppressor Smad4," Oncogene, vol. 26, no. 10, pp. 1417-1427, 2007.

[43] E. Hintermann and V. Quaranta, "Epithelial cell motility on laminin-5: regulation by matrix assembly, proteolysis, integrins and erbB receptors," Matrix Biology, vol. 23, no. 2, pp. 75-85, 2004.

[44] L. Borradori, S. Chavanas, R. Q. J. Schaapveld et al., "Role of the bullous pemphigoid antigen 180 (BP180) in the assembly of hemidesmosomes and cell adhesion-reexpression of BP180 in generalized atrophic benign epidermolysis bullosa keratinocytes," Experimental Cell Research, vol. 239, no. 2, pp. 463-476, 1998.

[45] J. C. R. Jones, S. B. Hopkinson, and L. E. Goldfinger, "Structure and assembly of hemidesmosomes," BioEssays, vol. 20, no. 6, pp. 488-494, 1998.

[46] Y. Hirako and K. Owaribe, "Hemidesmosomes and their unique transmembrane protein BP180," Microscopy Research and Technique, vol. 43, no. 3, pp. 207-217, 1998.

[47] K. Zhang and R. H. Kramer, "Laminin 5 deposition promotes keratinocyte motility," Experimental Cell Research, vol. 227, no. 2, pp. 309-322, 1996.

[48] B. P. Nguyen, X.-D. Ren, M. A. Schwartz, and W. G. Carter, "Ligation of integrin $\alpha 3 \beta 1$ by Laminin 5 at the wound edge activates Rho-dependent adhesion of leading keratinocytes on collagen," The Journal of Biological Chemistry, vol. 276, no. 47, pp. 43860-43870, 2001.

[49] S. Salo, A. Boutaud, A. J. Hansen et al., "Antibodies blocking adhesion and matrix binding domains of laminin-332 inhibit tumor growth and metastasis in vivo," International Journal of Cancer, vol. 125, no. 8, pp. 1814-1825, 2009.

[50] G. Giannelli, C. Bergamini, E. Fransvea, C. Sgarra, and S. Antonaci, "Laminin-5 with transforming growth factor- $\beta 1$ induces epithelial to mesenchymal transition in hepatocellular carcinoma," Gastroenterology, vol. 129, no. 5, pp. 1375-1383, 2005.

[51] G. B. Mills and W. H. Moolenaar, "The emerging role of lysophosphatidic acid in cancer," Nature Reviews Cancer, vol. 3, no. 8, pp. 582-591, 2003. 


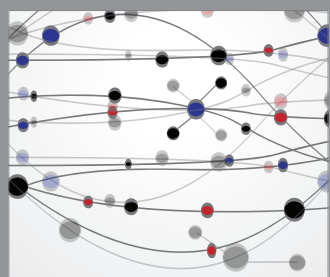

The Scientific World Journal
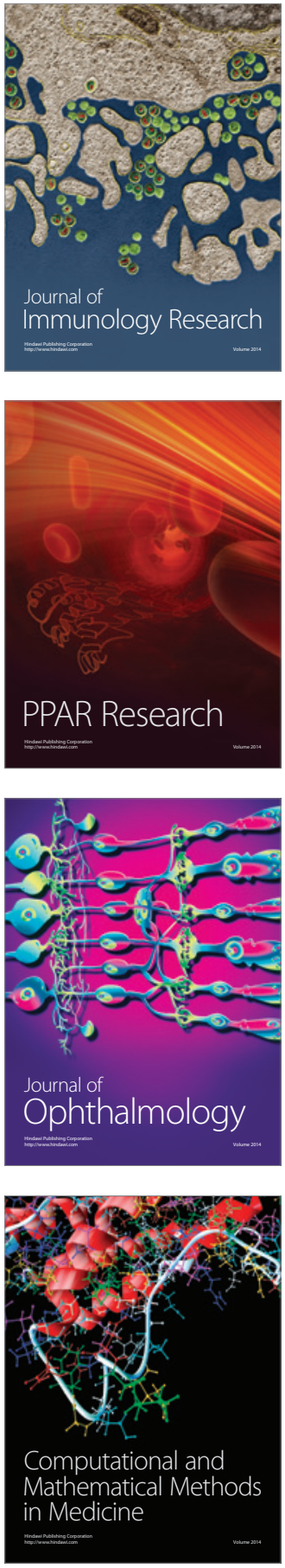

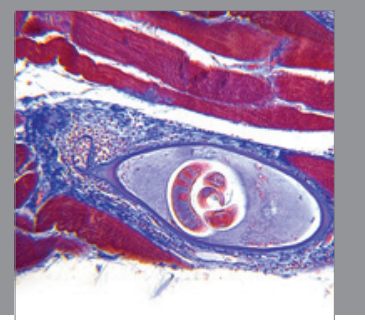

Gastroenterology

Research and Practice
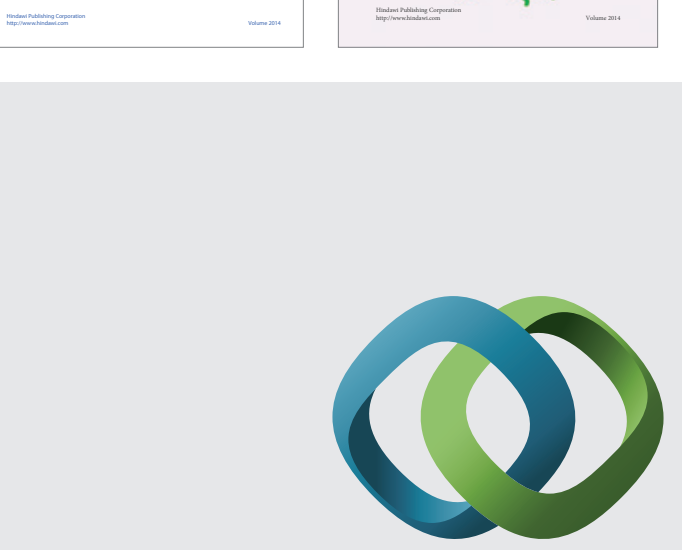

\section{Hindawi}

Submit your manuscripts at

http://www.hindawi.com
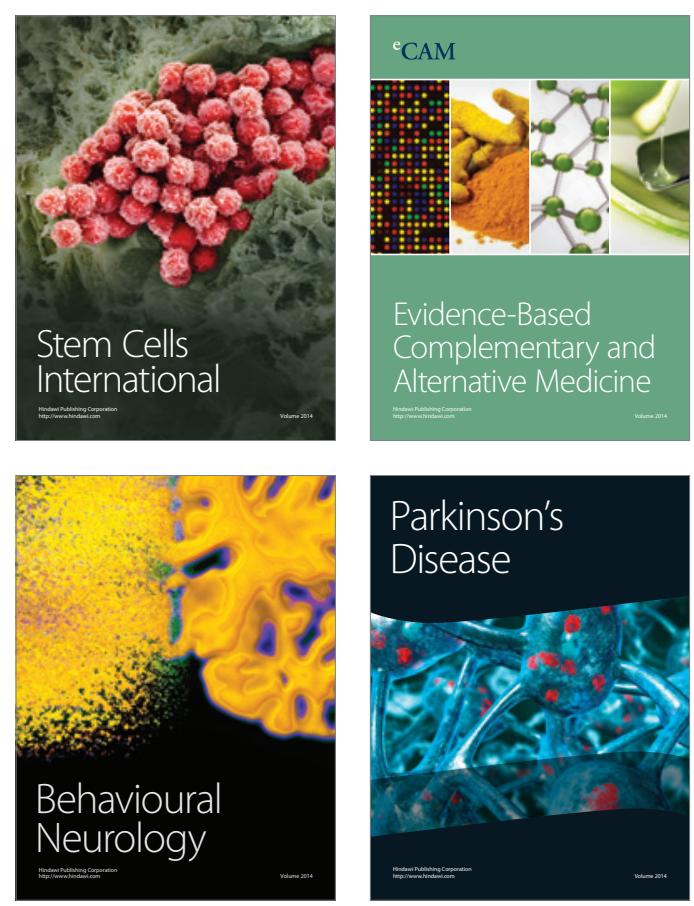

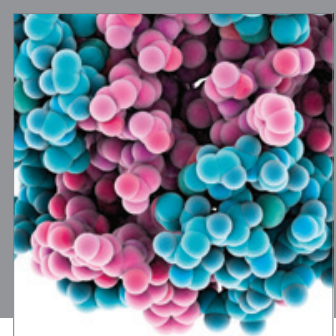

Journal of
Diabetes Research

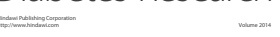

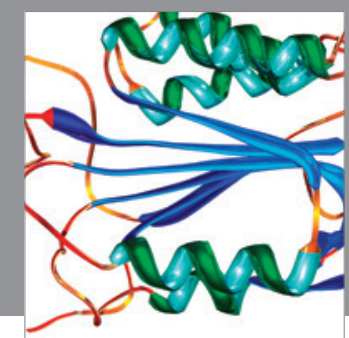

Disease Markers
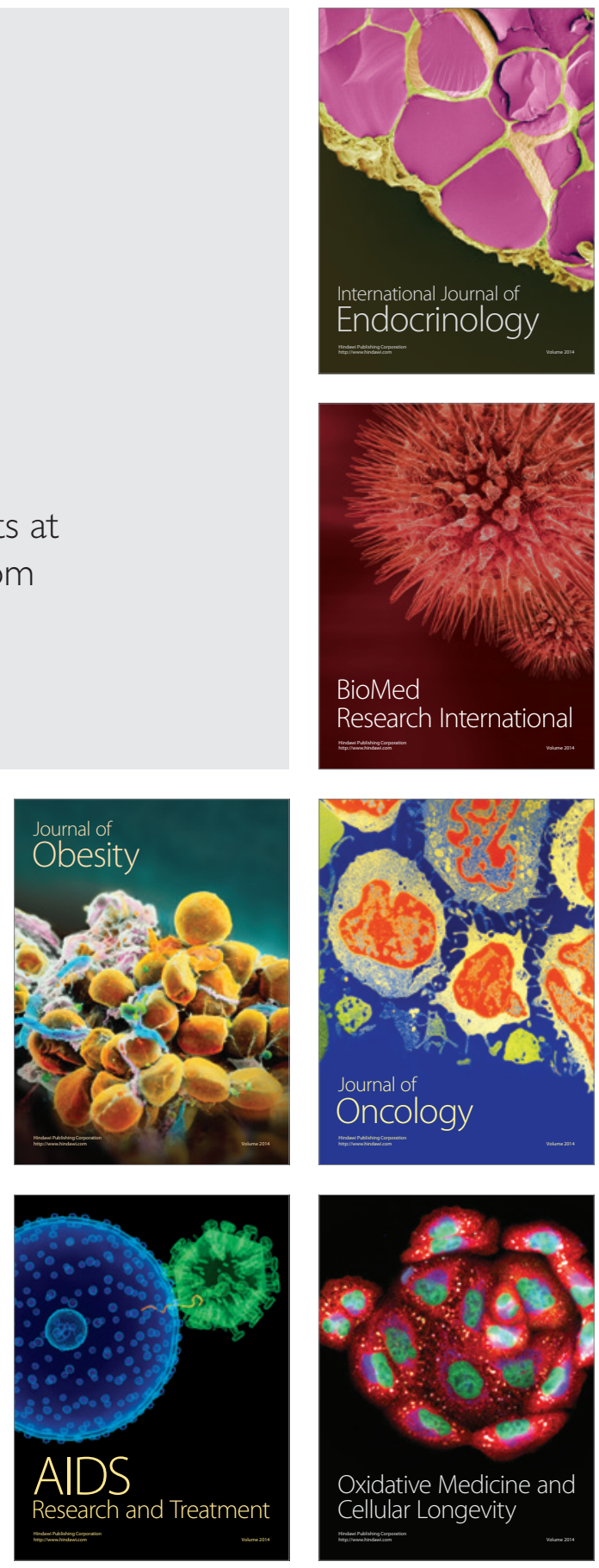